Rev Chil Anest 2017; 46: 167-170

\title{
Super obese patient undergoing minimally invasive mitral repair: Perioperative management
}

\author{
MARTA INÉS BERRIO V. ${ }^{1}$, IVÁN IGLESIAS²
}

\begin{abstract}
Obesity is an epidemic health issue showing increasing numbers all over the world. In the United States one third of adults are obese and $10 \%$ of health cost is related to obesity. Airway management, vascular access and positioning can be more challenging. Anaesthesiologists need to be prepared to the particular challenges these patients pose in cardiac rooms. Minimally invasive cardiac surgery (MICS) is an alternative to perform cardiac surgical procedures that has been related to decreased rate of infection and lower transfusion rates. This case report outlines the perioperative anesthetic management of a super obese patient undergoing a minimally invasive mitral valve repair.
\end{abstract}

\section{RESUMEN}

La obesidad es una problema epidémico de salud que ha aumentado en el mundo. En los Estados Unidos, un tercio de los pacientes adultos son obesos y un $10 \%$ del costo de salud es asociado a la obesidad. Los anestesistas necesitan estar preparados para los retos particulares que tiene estos pacientes en los pabellones cardiacos. La cirugía cardiaca mínimamente invasiva es una alternativa para realizar los procedimientos cardiacos con menor tasa de infección y transfusiones. Este reporte de caso describe el manejo anestésicos perioperatorio de un paciente super obeso para una cirugía mínimamente invasiva de la válvula mitral.
Key words: Surgery, minimally invasive; anesthesia, super obese, mitral valve insufficiency.

Palabras clave: Cirugía, mínimamente invasiva, anestesia, super obeso, insuficiencia mitral.

\footnotetext{
MD, MSc, Cardiac Anesthesia Fellow, Western University, London, Ontario, Canada.

2 MD, FRCPC, FASE, Cardiac Anesthesiologist. Associate professor. Western University. London Health Sciences Centre, London, Ontario, Canada.

From the Department of Anesthesia and Perioperative Medicine, University of Western Ontario, London, Ontario, Canada. Address correspondence to:

Marta Berrio

Room C3-111,

University Hospital, 339 Windermere Road, London, Ontario, Canada,

N6A5A5.

E-mail: martaberrio@gmail.com
} 


\section{Introduction}

Obesity is an epidemic health issue showing increasing numbers all over the world. In the United States one third of adults are obese and $10 \%$ of health cost is related to obesity ${ }^{1}$. Airway management, vascular access and positioning can be more challenging. Anaesthesiologists need to be prepared to the particular challenges these patients pose in cardiac rooms ${ }^{1}$. Minimally invasive cardiac surgery (MICS) is an alternative to perform cardiac surgical procedures that has been related to decreased rate of infection and lower transfusion rates. This case report outlines the perioperative anesthetic management of a super obese patient undergoing a MICS mitral valve repair.

\section{Case presentation}

A 53 year-old-male $182 \mathrm{~cm}$ tall, $173.5 \mathrm{~kg}$ weight, body mass index (BMI) $51.8 \mathrm{~kg} / \mathrm{m}^{2}$ patient was scheduled for an elective mitral valve repair through a right mini-thoracotomy. His previous history included hypertension, gastroesophageal reflux, shortness of breath NYHA class 2 with fatigue on exertion and he was a non-smoker. Upon examination: his blood pressure was 145/85 $\mathrm{mmHg}$, heart rate 64 beats/min, respiratory rate (RR) 18 breaths/min, oxygen saturation breathing air was $96 \%$. Airway exam showed beard and his Mallampati score was III). Electrocardiogram showed right bundle branch block. Preoperative echocardiogram demonstrated left ventricle normal size and function, ejection fraction $60-65 \%$, severe mitral regurgitation (MR) due to posterior leaflet prolapse, eccentric anteriorly-directed jet, P2 flail, posterior leaflet $18 \mathrm{~mm}$ in length. MR peak velocity of $1,27 \mathrm{mt} / \mathrm{sec}$, effective regurgitant orifice area (EROA) of $0,8 \mathrm{~cm}^{2}$ (Figure 1). Cardiac angiogram demonstrated normal coronary arteries. In the operating room external defibrillation pads were placed on, these are routine for MICS cases due to the lack of direct access to the heart. An awake left arterial radial line was inserted. For mitral valve MICS in our hospital we prefer to keep the right arm free of both arterial and venous access due to the right mini-thoracotomy approach used for surgery. Supplementary oxygen and sedation with midazolam were given for the arterial line placement. For endotracheal intubation the patient was placed on a troop elevation pillow (head elevated position). After adequate pre-oxygenation was secured, general anesthesia was induced with fentanyl 300 mcg, propofol $150 \mathrm{mg}$ titrated to bispectral index val- ues and rocuronium $150 \mathrm{mg}$. Intubation was achieved in one attempt with a 39Fr left double lumen tube using a Macintosh 4 blade, flexible fiberoptic bronchoscope was used to confirm tube position for lung isolation. Pressure-controlled ventilation was started, tidal volume (TV) $700 \mathrm{~mL}$, RR 12 breaths/min, oxygen inspiratory fraction $\left(\mathrm{FiO}_{2}\right)$ 80-100\%, positive end-expiratory pressure (PEEP) set at $10 \mathrm{cmH}_{2} \mathrm{O}$. Anesthesia was maintained with Isoflurane. A drop of saturation to $88 \%$ during one lug ventilation was improved with $\mathrm{FiO}_{2} 100 \%$ and increased PEEP, there was no need to use CPAP on the deflated lung. Double cannulation of the right internal jugular vein was performed. Intraoperative transesophageal echocardiography (ITEE) showed a localized prolapse of the lateral portion of P2 (Figures 2 and 3). A ring annuloplasty plus localized resection was performed (Figure 4), post bypass ITEE showed no residual MR. Perfusion and cross clamp times were 123 min and 86 min respectively.

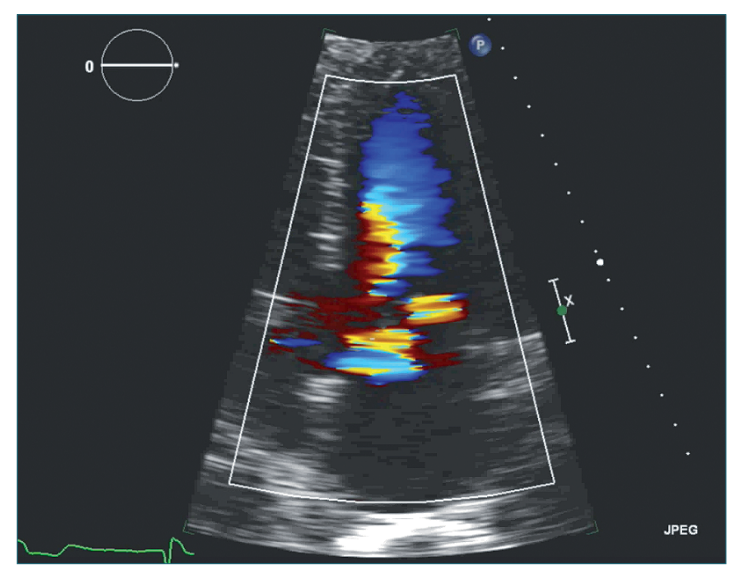

Figure 1.

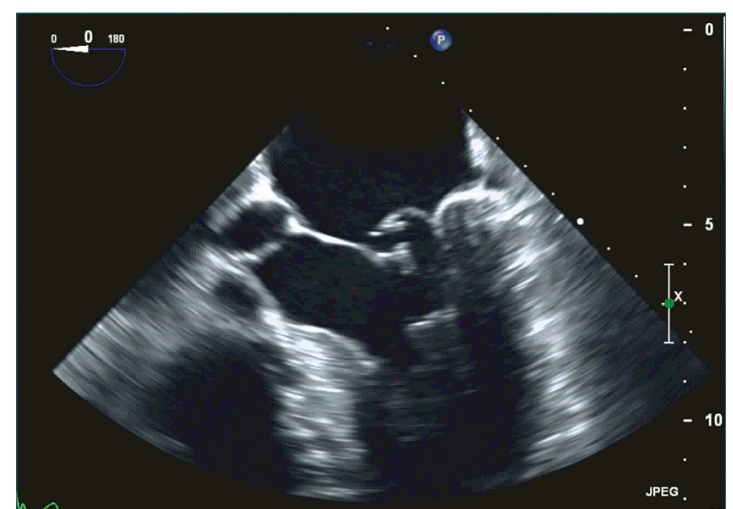

Figure 2. 


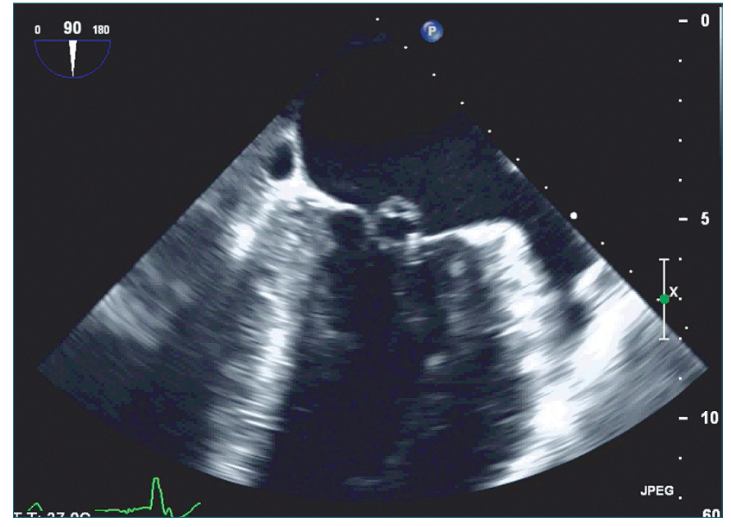

Figure 3.

Lung recruitment manoeuvres were performed after weaning from cardiopulmonary bypass and exchange of Robert Shaw tube for a single-lumen tube with a Glidescope videolaryngoscope at the end of the procedure. He was transferred to the intensive care unit (ICU) without pressors drugs and under sedation with propofol infusion. In the intensive care unit nitroglycerin was started because of hypertension; patient was extubated 10 hours after arrival in ICU and transferred to a general ward the next morning. The patient left the hospital in good condition 4 days after surgery.

\section{Discussion}

Perioperative management of super obese patient must take into account the comorbidities such as hypertension, coronary artery disease, heart failure, diabetes and sleep apnea ${ }^{2}$. These patients are more prone to wound infections, longer ventilator support in $\mathrm{ICU}^{2}$ and arrhythmias, predominantly secondary to sino-atrial node dysfunction and fatty infiltration of the conducting system specially atrial fibrillation ${ }^{3}$.

Obese patients have a decreased functional residual lung capacity, increased oxygen consumption and risk of atelectasis. An appropriated pre-oxygenation needs fresh flow gas set at a high range with pure oxygen, close-fitting face mask, avoid leaks showed by flaccid reservoir bag and abnormal capnography waveform and reach $90 \%$ end-tidal oxygen level ${ }^{4}$ during a 5-minute period ${ }^{2}$. The safe apnea period (SAP) is the time until the patient reaches an arterial saturation of $88-90 \%^{5}$. The SAP is 2.5 times shorter in obese patients compared to normal-weight patients (196 sec vs $595 \mathrm{sec})^{5}$.

Pre-oxygenation can be done with continuous

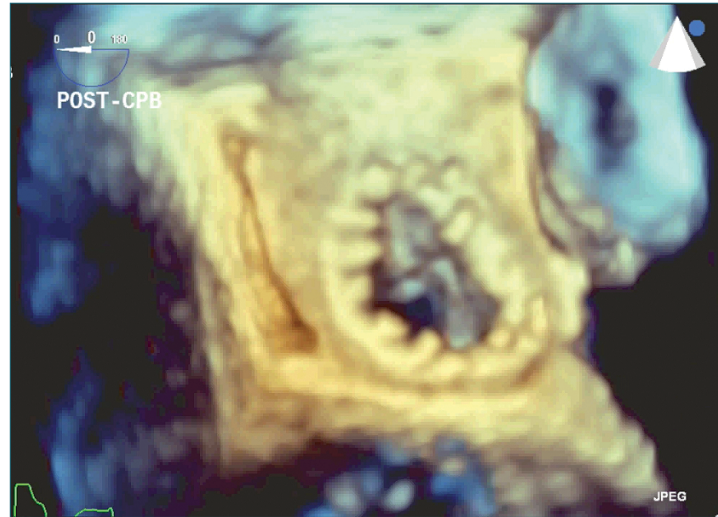

Figure 4.

positive airway pressure (CPAP) of $10 \mathrm{cmH}_{2} \mathrm{O}$ for 5 minutes as well ${ }^{4}$. The 25-degree head-up for patients with $\mathrm{BMI} \geq 40 \mathrm{~kg} / \mathrm{m}^{2}$ improves pre-oxygenation ${ }^{4}$. After intubation, a recruitment manoeuvre applying CPAP of $30-40 \mathrm{cmH}_{2} \mathrm{O}$ for $30-40$ seconds ${ }^{4}$ with a subsequent positive end-expiratory pressure reduces the incidence of atelectasis ${ }^{2}$ that in obese patients can reach $10 \%$ of the total lung volume after intubation $^{4}$.

A systematic approach is imperative for airway management. It is essential to have the appropriate equipment for positioning. The ramped position with the tragus of the ear leveled with the sternum facilitates pre-oxygenation and tracheal intubation ${ }^{3}$. Obesity is not per-se a predictor of difficult airway, however obstructive sleep apnea and obesity are risk factors for difficult bag-mask ventilation ${ }^{3}$. Equipment for difficult airway must be at hand if the patient has predictors for difficult laryngoscopy; flexible bronchoscope for confirmation of tube position for lung isolation is critical. It is recommended to have a back-up plan for intubation, in this case a large blade Glidescope was kept in the room for initial airway management.

Protective ventilation during one-lung ventilation can be a challenge. It is recommended a TV 6-8 mL/ kg IBW (ideal body weight), pressure-controlled ventilation ${ }^{2}$, plateau airway pressure $\leq 30 \mathrm{cmH}_{2} \mathrm{O}$, respiratory rate titrated to normocapnia, PEEP titrated to maximum dynamic compliance with recruitment manoeuvres and prepared for possible hypotension ${ }^{6}$.

Drug dosing should generally be based upon lean body weight and titrated to effect, rather than dosed to total body weight ${ }^{3}$. Propofol dose for induction, fentanyl and rocuronium must be based on lean body weight ${ }^{3}$. Anesthetic management for MR requires avoid bradycardia, preserve cardiac contractility, avoid 
increases in systemic and pulmonary vascular resistance ${ }^{8}$.

Operating room personnel should be trained to ensure correct position of the patient ${ }^{2}$. It is necessary a roll to slide the patient to the left side for the right anterior mini-thoracotomy and a safety strap. Soft foam or gel pads must be available in a sufficient manner to protect compression points ${ }^{2}$. The incidence of compression of sciatic and ulnar nerves are higher in obese patients ${ }^{2}$.

For minimally invasive cardiac surgery, the external pads for pacing/defibrillating are placed before induction, special care must be taken to keep the pads off the surgical access. Transesophageal echocardiography (TEE) is mandatory. TEE guides the femoral vein cannulation by confirming the location of the wire in the superior vena cava ${ }^{7}$. In our Institution is standard to place an additional venous drainage cannula through the right internal jugular vein ${ }^{8}$; intravenous heparin is given $(5,000 \mathrm{IU})$ to ensure ACT $>200$ before this cannula is inserted ${ }^{7,8}$.

Additional monitors in the operating room, connected to the thoracoscope, allow all members to see the mitral valve when the surgeon is exploring it and confirm ITEE findings? ${ }^{7}$.

Weaning from bypass requires ventilation of both lungs and recruitment manoeuvres (aimed both to de- air the heart and expand the collapsed lung) without excessive positive pressure. Evaluation of the mitral valve repair, biventricular function and aortic valve function is critical after CPB; the detection of new regional wall motion abnormalities by ITEE can be related to air in the right coronary artery. Occasionally damage to the circumflex artery can happen due to its location near to the annulus of the mitral valve ${ }^{8}$. The aortic valve is also close to the anterior leaflet of the mitral valve and its function can change after $\mathrm{CPB}^{8}$. Adequate paralysis and sedation is required to switch to a single-lumen tube before transferring the patient to ICU. It is important to remember that airway changes can have taken place during the case due to positioning (Trendelemburg), awareness of this means that endotracheal tube exchange must be very careful, tube exchangers and alternate airway devices are highly recommended in order to avoid loosing airway control at this step.

In summary, obesity is a global epidemic and cardiac operating rooms will experience increased frequency of these patients with their associated comorbidities. It is necessary to deliver an adequate standard of care to obese patients in order to reduce perioperative complications. We have outlined the perioperative anesthetic management of a super obese patient who underwent a successful minimally invasive mitral repair.

\section{References}

1. Minhaj MM, Zvara DA, Nayyar P, Maslow A. Case 1-2007 morbidly obese patient undergoing cardiac surgery. J Cardiothorac Vasc Anesth. 2007 Feb;21(1):133-43.

2. Bein B, Scholz J. Anaesthesia for adults undergoing non-bariatric surgery. Best Pract Res Clin Anaesthesiol. 2011 Mar;25(1):3751.

3. The Association of Anaesthetists of Great Britain and Ireland. Perioperative management of the morbidly obese patient.

4. De Jong A, Futier E, Millot A, Coisel $Y$, Jung $B$, Chanques $G$ et al. How to preoxygenate in operative room: healthy subjects and situations "at risk". Ann Fr Anesth Reanim. 2014 JulAug;33(7-8):457-61.

5. Berthoud MC, Peacock JE, Reilly CS. Effectiveness of preoxygenation in morbidly obese patients. Br J Anaesth. 1991 Oct;67(4):464-6.

6. Fernández-Bustamante $A$, Hashimoto S, Serpa Neto A, Moine P,
Vidal Melo MF, Repine JE. Perioperative lung protective ventilation in obese patients. BMC Anesthesiol. 2015 May;15(1):56

7. Malik V, Jha AK, Kapoor PM. Anesthetic challenges in minimally invasive cardiac surgery: are we moving in a right direction? Ann Card Anaesth. 2016 Jul-Sep;19(3):489-97.

8. Vernick WJ, Woo JY. Anesthetic considerations during minimally invasive mitral valve surgery. Semin Cardiothorac Vasc Anesth. 2012 Mar;16(1):11-24. 